\title{
Artigo
}

\section{0 anos de crise: um novo momento de transição no sistema internacional?}

\author{
10 years of crisis: a new moment of transition in the international system?
}

Fernanda de Castro Brandáo Martins ${ }^{3}$

DOI: $\underline{10.5752 / P .1809-6182.2018 \mathrm{v} 15 . n 2 . p 3}$

Recebido em: 17 de julho de 2018 Aceito em: 11 de dezembro de 2018

\begin{abstract}
Resumo
A crise de 2008 pode ser entendida como um evento que evidencia o retorno do sistema internacional a um momento de transição e mudança. Assim, esse artigo busca entender em que medida a crise pode ser vista como um marco do retorno a um novo momento de transiçáo.
\end{abstract}

Palavras-chave: crise financeira, hegemonia, transição

\begin{abstract}
he 2008 crisis can be understood as an event that points to a new moment of transition and change in the international system. This article aims to understand if this crisis can be understood as a hallmark of a new moment of transition in the system.
\end{abstract}

Key words: financial crisis, hegemony, transition

3. Doutoranda do Programa de Pós-Graduação em Relaçôes Internacionais da Universidade do Estado do Rio de Janeiro. Bolsista FAPERJ. Mestre em Relações Internacionais pela Universidade Federal da Bahia e Bacharel pela Pontifícia Universidade Católica do Rio de Janeiro. Foi estagiária de pesquisa no BRICS Policy Center no núcleo de finanças, desenvolvimento, investimento e comércio. ORCID: 0000-0001-8343-4020 


\section{Introdução}

Em 2018, a maior crise financeira internacional desse a crise de 1929 completa 10 anos, tornando possível avaliar os efeitos da crise sobre a governança financeira internacional e qual seu papel no processo de mudança e transição no sistema internacional. A crise pode ser entendida como um evento que contribuiu para o aumento da percepção do declínio do poder e da liderança dos Estados Unidos no sistema internacional. O papel da China no cenário pós-crise, juntamente com outros países emergentes, levantou a possibilidade de que haja uma nova transição de liderança hegemônica no sistema. Nesse sentido, pode-se argumentar que a crise financeira de 2008 pode até ter chegado ao seu fim, mas o processo de transiçẫo está apenas no começo. Partindo do entendimento de que a estabilidade do sistema financeiro internacional depende da existência de uma liderança hegemônica, a expectativa é de que crises e instabilidades sejam recorrentes no sistema até a conclusão do processo de transição. A crise não colocou fim à hegemonia americana, mas tornou evidente as contradiçóes e vulnerabilidades da ordem sustentada pela hegemonia estadunidense também mostrou que o eixo de poder econômico internacional vem se deslocando progressivamente do Atlântico para o Oceano Pacífico, com destaque para a China.

O objetivo desse artigo é observar como a crise aponta para a existência de um novo momento de transição e mudança na ordem internacional, onde há declínio lento e contínuo do poder estadunidense, ao mesmo tempo que a China emerge como potencial futuro líder hegemônico. Assim, analisando a atuação de ambos os países na governança financeira internacional no pós-crise busca-se identificar evidências do processo de transição. A hipótese é que, após a crise, a China passou a atuar de forma mais efetiva para promover a estabi- lidade do sistema financeiro internacional ao passo que os Estados Unidos parecem perder o posto de liderança absoluta sobre esse processo de governança, apontando para uma transição no posto de hegemonia do sistema.

$\mathrm{O}$ artigo divide-se em três sessões além desta introdução e da conclusão. Primeiro, discute-se a relação entre hegemonia, estabilidade no sistema financeiro e monetário internacional e a crise. Depois, discute-se o impacto da crise sobre as instituições de governança financeira internacionais. Faz-se então uma breve análise sobre o que a crise representou para a China e para a hegemonia estadunidense.

\section{Hegemonia, estabilidade e a crise}

A existência de uma liderança hegemônica é entendida como condição necessária para a estabilidade e pleno funcionamento da governança do sistema financeiro e monetário internacional. De acordo com Charles Kindleberger (1986), para que a economia mundial esteja estabilizada é preciso que haja um estabilizador, uma única grande potência que exercerá o papel de liderança hegemônica no sistema internacional. Essa estabilidade é consequência do estabelecimento de arranjos sociais, econômicos e políticos pelo poder hegemônico para sustentar sua liderança sobre o sistema internacional (GILPIN, 1981). De forma, que a estrutura de governança internacional reflete a distribuição de poder no sistema e reforça a liderança do poder hegemônico.

O período entre guerras evidencia a relaçáo entre ausência de liderança hegemônica e instabilidade, tendo sido caracterizado pela inabilidade dos governos em concordar sobre as medidas necessárias para a restauração da estabilidade econômica internacional após a crise de 1929 (RAVENHILL, 2010). O motivo para essa confusão e dificuldade 
de cooperação pode ser entendido pela ausência de um poder hegemônico que exercesse a liderança efetiva no momento, uma vez que a Grá-Bretanha se encontrava em declínio e enfraquecida pela guerra e os Estados Unidos ainda não haviam assumido a responsabilidade de liderança no sistema internacional condizente com suas capacidades de poder. A existência de uma liderança hegemônica exercida por um país era condição necessária para a estabilizaçáo da economia internacional e retorno da cooperação (KINDLEBERGER, 1986).

A liderança dos EUA como poder hegemônico só iniciou com o fim da Segunda Guerra Mundial quando passou a atuar efetivamente a fim de restaurar os fluxos internacionais de bens e capitais. A decisão de exercer a liderança foi fruto tanto do constrangimento sistêmico resultante do protecionismo e da recorrência de crises financeiras quanto dos constrangimentos domésticos, uma vez que o país precisava de uma economia internacional estabilizada para dar continuidade ao seu crescimento econômico e o desenvolvimento industrial do país (MARTINS, 2017). Esse fato mostra que a acumulação de capacidades de poder não é automaticamente traduzida em influência sobre o sistema internacional, precisando-se que haja a decisão de liderar do novo poder hegemônico e do reconhecimento dos demais países do novo líder.

Os EUA criaram uma série de arranjos socias baseados em seus princípios e valores a fim de construir um arcabouço para o gerenciamento da economia internacional facilitando o exercício de sua liderança hegemônica. Foram criadas instituiçóes multilaterais internacionais com o objetivo de facilitar a cooperação e a coordenação das políticas macroeconômicas entre os estados, a saber, o Fundo Monetário Internacional (FMI), o Banco Internacional para Reconstrução e Desenvolvimento (BIRD - precursor do Grupo do Banco Mundial) e o Acordo Geral sobre Comércio e Tarifas (GATT, do inglês - precursor da OMC). Essas instituições foram criadas fundamentadas em princípios como o multilateralismo, a primazia do direito e o liberalismo econômico e refletindo a distribuição de poder do momento de sua criação, principalmente o FMI e o BIRD. Essa estrutura perdurou de forma relativamente sólida até a crise de 2008.

Partindo dos pressupostos da estabilidade hegemônica, quando houver declínio do poder hegemônico, haverá retorno de crises e instabilidade na economia internacional. Nesse sentido, a crise de 2008 pode representar um evento sintomático do retorno do sistema internacional a um período de transição. A crise reforçou a percepção de declínio lento e contínuo do poderio dos EUA e sua influência sobre a economia internacional, ao mesmo tempo que apontou para a emergência de novos atores como fundamentais para manutenção da estabilidade econômica internacional, principalmente a China e outros países em desenvolvimento (ex: Brasil e Índia).

A crise de 2008 teve origem nos Estados Unidos e afetou principalmente países desenvolvidos, ou seja, surgiu da principal economia do globo, até então, sinônimo de solidez. Entre os motivos da crise destacam-se a falta de mecanismos financeiros regulatórios suficientes e a falta de coordenação macroeconômica entre as economias dos países desenvolvidos (RAMOS et al., 2012). Uma das consequências da crise foi o aumento da preocupação com a manutençẫo da estabilidade financeira não apenas nas economias em desenvolvimento, mas também nas economias desenvolvidas, dantes consideradas fonte de estabilidade para o sistema financeiro internacional (HENNING \& WALTER, 2016).

Como consequência, registrou-se em 2009 uma queda de $0,8 \%$ no PIB mundial (queda semelhante fora vista apenas na crise dos anos 1930), 12\% nos fluxos de comércio internacional e $40 \%$ nos fluxos de investimento externo direto 
(RAVENHILL, 2011). A queda na demanda por produtos manufaturados nos países desenvolvidos levou a uma reduçáo na demanda por commodities por países emergentes como Índia e China, consumidores vorazes de tais produtos, levando à queda do preço das commodities nos mercados internacionais afetando negativamente países menos desenvolvidos. Assim, a crise evidenciou o grau de interdependência entre os países resultante do intenso processo de globalização da economia internacional e como crises podem ter rápido contágio, principalmente, se originadas na economia central do globo.

O período posterior a crise mostrou a insuficiência dos EUA e demais países desenvolvidos para a contenção da mesma e restauração do equilíbrio internacional sem a inclusão dos países emergente, uma vez que, por terem sido menos atingidas pela crise devido a menos exposição ao mercado de subprimes estadunidense mantendo o crescimento econômico, a contribuição financeira desses países foi fundamental na diminuição dos impactos da crise e sua contenção. A China recebeu destaque pela sua atuação como fonte de liquidez internacional, papel geralmente exercido pelo líder hegemônico do sistema (KINDLEBERGER, 1986), inclusive complementando o capital disponível nas instituiçôes financeiras tradicionais através de transferências de capital.

Assim, o momento da crise de 2009 aponta para sinais de uma nova transição como consequência da redistribuição de poder no sistema uma vez que o poder hegemônico passa a ter sua liderança questionada ao ser percebido como potencial fonte de instabilidade para a economia internacional devido às suas vulnerabilidades econômicas, além de evidenciar sua incapacidade de continuar exercendo de forma efetiva a liderança do sistema financeiro e monetário internacional sem a participaçáo de países emergentes, que se confirma ao olharmos para os efeitos da crise nas instituiçôes de governança financeira internacionais, objetivo da próxima seção.

Há autores que entendem que o impacto da crise financeira de 2008 tem sido exagerado em relação ao declínio da hegemonia estadunidense uma vez que essa crise foi orgânica e iminente no capitalismo neoliberal tendo trazido, na realidade, a reconstituição dos componentes social, político e geográfico da hegemonia neoliberal americana (SAULL, 2012). Todavia, é inegável que a crise colocou pressão sobre o exercício da liderança estadunidense e mostrou que novos atores, como os países emergentes e, principalmente, a China, precisam ser agregados no processo de governança financeira internacional. Nesse sentido, a crise levou a mudanças na estrutura de governança internacional, que podem ser entendidas também como resultando de mudanças na distribuição de poder no sistema, processo que é parte da transição.

\section{Impactos da crise nas instituições financeiras internacionais: outros sinais de transição?}

A crise evidenciou a emergente e cada vez mais importante contradiçẫo entre a distribuição de poder no sistema internacional e a hierarquia de poder cristalizada nas instituiçôes financeiras tradicionais evidenciando o um déficit representativo dos países emergentes nas principais instituiçōes financeiras internacionais, de forma que não possuem influência corresponde à sua participação na economia internacional. Os EUA e outros países desenvolvidos têm o domínio sobre essas instituições, o que é evidenciado pelo poder de veto dos Estados Unidos e pela super-representação dos países europeus em relação à participação desses países na economia mundial no FMI e no Banco Mundial. É interessante notar que dentre as áreas de governança econômica internacional, 
o âmbito financeiro e monetário é onde a marginalização dos países em desenvolvimento é mais evidente e institucionalizada. Enquanto na OMC as decisões são tomadas por consenso, no FMI e no Banco Mundial as decisões são tomadas por maioria e os países possuem diferentes cotas de votação; o Comitê de Basiléia para Supervisão Bancária tem participação majoritária de economias desenvolvidas; e o próprio G7 não inclui os países em desenvolvimento.

A contradiçẫo identificada é uma característica de momentos de transição no sistema internacional uma vez que são marcados pela existência de uma distribuição de poder que já não corresponde à hierarquia de poder consolidada nas instituiçóes internacionais (MARTINS, 2017). Nesse sentido, os países emergentes, principalmente, a China, têm buscado aumentar sua influência sobre a governança financeira internacional a fim de que esta corresponda à importância desses países na economia internacional. A necessidade de maior participaçáo dos países em desenvolvimento na governança financeira internacional já havia sido percebida nos anos 1990 com a crise do México e a crise asiática (RAMOS et al., 2012). A crise de 2008 mostrou a insustentabilidade do sistema vigente e a necessidade de melhor inclusão dos países emergentes no processo de governança financeira internacional, principalmente diante do papel exercido por essas economias no momento pós-crise.

Nesse sentido, a consolidação do G20 financeiro e avanços na reforma das cotas do FMI apontam para ajustes no sentido de adequar a estrutura de governança à nova distribuição de poder, mas ainda de forma limitada. O G20 fora criado após a crise financeira asiática de 1997 como uma reunião de ministros de finanças e presidentes dos bancos centrais das 20 principais economias do mundo. Após a crise de 2008, o G20 passou a contar com reuniōes dos chefes de estado dos países membros e o fórum ofuscou o G8 como principal espaço decisório da governança financeira internacional. A reforma das cotas de votação do FMI em 2010 não alterou significativamente a realidade da instituição. Após a reforma, Brasil, Rússia, China e Índia passaram a configurar entre as 10 maiores cotas, mas os EUA permanecem com poder de veto e a Europa continua sendo super-representada na instituição. Nem mesmo se somadas as cotas dos países BRICS é possível alcançar o poder de veto que os EUA possuem.

A crise mostrou também o lado negativo da dependência do dólar, moeda patrocinada pelo poder hegemônico, como principal reserva de valor. A China, juntamente com outros países em desenvolvimento, passou a pressionar para o aumento da utilização dos Direitos Especiais de Saques (SDR do inglês), ao mesmo tempo que deu novo vigor ao processo de internacionalização da sua moeda doméstica, o RMB, no intuito de diminuir a dependência do dólar. No G20, juntamente com a Rússia, a China tem argumentado por um sistema monetário menos dependente do dólar americano (HENNING \& WALTER, 2016).

Outro fenômeno do sentido de ajuste da governança financeira internacional à distribuição de poder emergente é a criação de instituições ao mesmo tempo alternativas e complementares às instituições tradicionais patrocinadas pelos BRICS e pela China. Logo, a criação do Novo Banco de Desenvolvimento e do Arranjo Contingente de Reservas dos BRICS e do Banco Asiático de Investimento em Infraestrutura (AIIB do inglês) se encaixa entre as instituiçóes criadas com o intuito de aumentar a influência da China e dos países emergentes sobre a governança financeira internacional. A proposição dessas instituiçóes é fruto de insatisfação com o lento caminhar das reformas nas instituições tradicionais (ROBERTS et.al, 2018). O sucesso dessas instituições confirmará a importância da China e 
dos BRICS como atores indispensáveis da governança financeira internacional.

\section{O momento de transição e os efeitos da crise}

A crise se encaixa de forma clara no processo de transição entre lideranças hegemônicas resultante da redistribuição de poder no sistema. A crise mostrou que a liderança do então poder hegemônico já não é mais suficiente para garantir a estabilidade das finanças internacionais sendo necessária a participação das potências emergentes. Assim, a crise revelou a contradição entre a estrutura de governança existente e a estrutura de poder emergente no sistema.

A China não saiu completamente ilesa da crise, tendo as vulnerabilidades da sua economia expostas como a forte dependência de exportaçóes e a alta exposição ao dólar, por exemplo. O principal impacto da crise na China foi a queda no investimento externo direto (IED) e na demanda por exportaçóes, principalmente pelos países desenvolvidos, uma vez que o mercado financeiro chinês tinha pouca exposição ao mercado de subprimes americano (CHOW, 2010). Logo, mostrou-se a necessidade de repensar o modelo de desenvolvimento do país a fim de diminuir essas dependências externas que aumentam o risco de exposição da economia chinesa a choques internacionais. $\mathrm{O}$ governo chinês tem buscado aumentar a demanda doméstica e diversificar seus parceiros comerciais a fim de diminuir a dependência em relação aos países desenvolvidos, além do esforço de internacionalização da moeda do país. Apesar desses esforços, o RMB ainda represente um pequeno percentual das transações internacionais e o dólar continua sendo a moeda predominante do sistema (PRASAD 2017). Através da continuidade da internacionalização da sua moeda, a China se beneficiará da imagem de um país estável e poderá aumentar sua influência sobre o processo decisório das finanças internacionais (BERNDZEN, 2017). Contudo, a continuidade e sucesso dessa reforma serão determinantes para consolidar a preponderância da China na economia internacional.

A posição da China como possível novo poder hegemônico ainda é bastante questionada levantando-se a profunda interdependência entre as economias chinesa e americana como um entrave (SAULL, 2012). Além disso, o país ainda possui um longo caminho a percorrer para alcançar o mesmo nível de desenvolvimento econômico e superar as capacidades de poder estadunidenses, principalmente militares.

Como resultado da crise a China se encontra em uma posição de maior proeminência e influência na governança economia internacional do que antes da crise. A atuação do governo chinês ao incentivar a atividade econômica doméstica foi fundamental para sustentar a demanda internacional e amenizar os efeitos da crise juntamente com a provisão de liquidez no período pós-crise e na estabilização da zona do euro. Esse prestígio aumenta o interesse dos demais países nas novas instituições financeiras promovidas pela China como o AIIB e as instituiçóes dos BRICS como o CRA e o NDB. Dessa forma, o âmbito financeiro das relaçôes econômicas internacionais tem se mostrado um importante meio para obtenção de maior poder geopolítico para China que passou a atuar de forma efetiva nesse sentido através da criação das instituições financeiras mencionadas e do maior esforço para internacionalização do RMB (PRASAD, 2017). Houve, também, mudança na postura das instituições internacionais em relação à China. Anteriormente o país era continuamente criticado pelo FMI por não aderir às políticas do Consenso de Washington, após a crise e o relevante papel desempenhado pela China na recuperação da economia global, Andrew Walter (apud HENNING \& WALTER, 2016) observa que a instituição passou 
a adotar uma postura de menor confrontamento às políticas cambiais chinesas, por exemplo.

Já para os EUA, a crise teve importante impacto sobre a percepçáo da sua capacidade de liderar o sistema (IKENBERRY, 2011). A crise abalou fortemente o poder americano e o seu soft power, mas o país ainda continua sendo essencial para o gerenciamento do sistema financeiro internacional (NYE, 2015). Ainda assim, os países em desenvolvimento hoje podem participar mais ativamente da determinação dos padrōes de governança financeira, apesar das limitações em relação a ausência de experiência desses países nesse âmbito (HYOUNG-KYU, 2016).

Apesar da crise apontar para atritos na continuidade da liderança hegemônica dos EUA sobre a economia internacional, esta não pode ser interpretada como o marco final da hegemonia estadunidense, afinal o dólar continua sendo a principal moeda de reserva internacional e o país continua exercendo papel fundamental na governança econômica internacional. Ao mesmo tempo que houveram mudanças em termos de representatividade no sentido da inclusão de novos atores emergentes no processo decisório, as bases valorativas do modelo neoliberal prevalecente na economia internacional, promovido pelos EUA, foram reafirmadas (RAMOS et al., 2012). Porém, a continuidade do sucesso do modelo alternativo chinês, progressivamente diminuirá o poder atrativo do modelo americano (BERNDZEN, 2017).

Momentos de instabilidade têm sido mais frequentes no sistema financeiro internacional podendo ser argumentado que não houve restauração plena da estabilidade até o momento. A ideia de que a estabilidade do sistema financeiro foi restaurada se mostra um tanto "wishful thinking" diante de rumores de crise da dívida e crises cambiais na Argentina, Turquia e outros países emergentes e até mesmo em economias desenvolvidas como a Itália, relacionadas à política dos EUA de normalizaçáo das taxas de juros (ROGOFF, 2018). A atuação do líder hegemônico continua sendo fonte de potencial instabilidade, principalmente diante da postura unilateralista do governo Trump. Esses rumores de crise levantam, também, questionamentos quanto a eficiência e capacidade das instituições tradicionais, principalmente o FMI, de prover os recursos necessários diante de uma nova crise internacional.

\section{Conclusão}

A crise de 2008 pode ser entendida como um marco que evidência um novo momento de transição entre lideranças hegemônicas no sistema internacional. Nesse sentido, a crise apontou para a inabilidade do poder hegemônico em continuar garantindo a estabilidade da economia internacional sendo, inclusive, a fonte de instabilidade e de crise. Assim, a crise colocou no holofote a contradição existente entre a estrutura de governança internacional no sistema financeiro e monetário e a nova distribuiçâo de poder existente indicando que o alcance da estabilidade nas finanças internacionais cada vez mais depende de uma atuação mais ativa dos países emergentes no processo de governança. Esse processo resultou na consolidaçáo do G20, na reforma da representatividade no FMI e na criação de novas instituiçôes alternativas e complementares no sistema financeiro internacional patrocinadas pela China e pelos BRICS. A crise também foi importante impulsionador para que a China assumisse uma posição mais ativa e assertiva nesse âmbito na economia internacional onde permanecia marginalizada. Assim, a crise pode não marcar o fim da hegemonia estadunidense, mas pode ser identificada como um evento característico do período de transição no sistema internacional. A expectativa, porém, é que os anos de instabilidade continuem e crises sejam recorrentes até que o processo de transição seja concluído. 


\section{Referências}

BERNDZEN, Anke. The "Asia-Pacific Dream": Is China Using Economic Integration Initiatives as Ideological Weapons? - On the link between Free Trade Agreements, Soft Power and "Universal Values". Journal of China and International Relations, v., n.1, p1-34, 2017.

CHOW, Daniel. China's Response to the global financial crisis: implications for U.S.-China economic relations. Global Business Law Review, v.1, n.47, p.48-81, 2010.

GILPIN, Robert. War and Change in World Politics. Nova York: Cambridge University Press, 272 p. 1981

HENNING, C. Randall \& WALTER, Andrew. Introduction and Overview: Global Governance and the Changing Structure of International Finance. In: (ed.). Global Financial Governance Confronts the Rising Powers: emerging perspectives on the new G20. Waterloo: Center for International Governance Innovation, 335p. 2016

HYOUNG-KYU Chey. International Financial Standards and Emerging Economies Since the Global Financial Crisis. In: HENNING, C. Randall \& WALTER, Andrew (ed.). Global Financial Governance Confronts the Rising Powers: emerging perspectives on the new G20. Waterloo: Center for International Governance Innovation, P.211-235.2016

IKENBERRY, John G. Liberal Leviathan: The origins, crisis, and transformation of the American World Order. Princeton, Princeton University Press, 372p. 2011

KINDLEBERGER, Charles P. The world in depression, 1929-1939. Berkley: California University Press, 305 p. 1986

MARTINS, Fernanda de C. B. A ascensáo chinesa e o sistema financeiro e monetário internacional: rumo a um potencial novo ciclo de hegemonia? Dissertaçáo (Mestrado em Relaçōes Internacionais) - Instituto de Humanidades, Artes e Ciências Professor Milton Santos, Universidade Federal da Bahia, Salvador. 2017

NYE, Joseph S. Jr., Is the American century Over? Cambridge: Polity Press. 146 p. 2015

PRASAD, Eswar W. Gaining Currency: The Rise of the Renminbi. Nova York: Oxford University Press. Versão digital kindle. 2017

RAMOS, Leonardo; VADELL, Javier; SAGGIORO, Ana \& FERNANDES, Márcia. A governança econômica global e os desafios do G-20 pós-crise financeira: análise das posiçôes de estados Unidos, China, Alemanha e Brasil. Revista Brasileira de Política Internacional, v.55, n. 2, p.10-27, 2012.

RAVENHILL, John. The Study of Global Political Economy. In: __ (ed.). Global Political Economy, 3a edição. Oxford: Oxford University Press. 532p. 2016

ROBERTS, Cynthia; ARMIJO, Leslie E. \& KATADA, Saori N. The BRICS and Collective Financial Statecraft. Oxford University Press. 260 p. 2018
ROGOFF, Kenneth. Are Emerging Markets the Canary in the Financial Coal Mine? Project Syndicate. 6 de junho de 2018. <https://www.project-syndicate.org/commentary/ will-emerging-markets-trigger-global-debt-crisis-by-kenneth-rogoff-2018-06? utm_source=Project + Syndicate + Newsletter\&utm_campaign=b218ae6fd5 -sunday_newsletter_10_6_2018\&utm_medium=email\&utm_term=0_73bad5b7d8-b218ae6fd5-93500473> Acesso: 18 jun, 2018

SAULL, Richard. Rethinking Hegemony: Uneven Development, Historical Blocs, and the World Economic Crisis. International Studies Quaterly, n. 56, p.323-338, 2012. 